\title{
Superiority of NBI endoscopy to PET/CT scan in detecting esophageal cancer among head and neck cancer patients: a retrospective cohort analysis
}

Hsuan-An Su', Shun-Wen Hsiao ${ }^{2}$, Yu-Chun Hsu², Lien-Yen Wang ${ }^{3}$ and Hsu-Heng Yen ${ }^{2,4,5^{*}}$ (D)

\begin{abstract}
Background: Second primary cancer of the esophagus is frequent in head and neck patients, especially in high-risk populations, and has a great impact on the prognosis. Although Positron emission tomography (PET)/computed tomography (CT) scan is commonly conducted in head and neck patients, its ability to detect early esophageal cancer is limited. Narrow-band imaging endoscopy is an accurate and convenient technique for esophageal examination. We aimed to compare PET/CT scan and narrow-band imaging endoscopy for the detection of esophageal cancer in head and neck cancer patients.
\end{abstract}

Methods: From November 2015 to November 2018, all head and neck cancer patients who underwent both PET/CT scan and narrow-band imaging endoscopy at Changhua Christian Hospital were retrospectively enrolled. Descriptive statistics, receiver operating characteristic curve analysis, logistic regression analysis, independent Student's t-test, and Kaplan-Meier survival analysis were conducted with MedCalc Statistical Software.

Results: A total of 147 subjects were included in the analysis; suspicious esophageal lesions were identified by PET/CT scan in 8 (5.44\%) and by narrow-band imaging in 35 (23.81\%). The final pathologic diagnoses were esophageal squamous cell carcinoma in 10 and high-grade dysplasia in 5. The respective sensitivity, specificity, and area under the curve for detecting suspicious esophageal lesions were 33.33, 97.73\%, and 0.655 for PET/CT scan, and 100.0, 84.85\%, and 0.924 for narrow-band imaging endoscopy. Hypopharyngeal or laryngeal location of the primary head and neck cancer was the only risk factor for developing second primary esophageal cancer.

Conclusions: PET/CT scan was inferior to narrow-band imaging endoscopy in detecting second primary esophageal cancer in head and neck cancer patients. In addition to PET/CT scan, narrow-band imaging endoscopy should be considered in head and neck patients at high risk for developing second primary esophageal cancer.

Keywords: PET/CT scan, Narrow-band imaging, Endoscopy, Head and neck cancer, Screening, Second primary cancer, Squamous cell carcinoma, Esophageal cancer

* Correspondence: 91646@cch.org.tw; blaneyen@gmail.com

2Endoscopy Center, Changhua Christian Hospital, 135 Nanhsiao Street,

Changhua, Taiwan

${ }^{4}$ Institute of Medicine, Chung Shan Medical University, Taichung, Taiwan

Full list of author information is available at the end of the article

(c) The Author(s). 2020 Open Access This article is distributed under the terms of the Creative Commons Attribution 4.0 International License (http://creativecommons.org/licenses/by/4.0/), which permits unrestricted use, distribution, and reproduction in any medium, provided you give appropriate credit to the original author(s) and the source, provide a link to the Creative Commons license, and indicate if changes were made. The Creative Commons Public Domain Dedication waiver (http://creativecommons.org/publicdomain/zero/1.0/) applies to the data made available in this article, unless otherwise stated. 


\section{Background}

Head and neck cancers (HNC) account for approximately $3.7 \%$ of all cancers and $2.4 \%$ of all cancer-related deaths in both sexes in the United States [1]. In Taiwan, HNC accounts for approximately $10 \%$ of all cancers, with a 7.3fold higher incidence in men than in women, and about $8.2 \%$ of all cancer-related death in both sexes [2]

Second primary cancers (SPC) in the respiratory and gastrointestinal tracts, such as the lungs and the esophagus, had been frequent in patients with HNC. SPC of the esophagus was shown to develop in about 7.4 to $51.5 \%$ of HNC patients [3-5], with a relative risk of 23 among oral cancer patients [6] and a standardized 5.9fold higher risk in HNC patients, compared with the baseline incidence [7]. The existence of a second primary esophageal squamous cell carcinoma (ESCC) had been reported as an independent detrimental prognostic factor in HNC patients and significantly reduced overall survival, with hazard ratios ranging from 1.53 to 2.75 [8-14]. Early detection of SPC of the esophagus, endoscopic resection, and implementation of pretreatment endoscopic screening policy had been shown to significantly improve the survival rates of HNC patients, especially among Asians $[9,12,13,15]$.

Endoscopy with narrow-band imaging (NBI) is one of the virtual chromoendoscopic techniques that enhance blue and green light to highlight abnormal neoplastic vasculatures, based on the different optic absorbability values of hemoglobin at certain wavelengths [16]. NBI endoscopy had been shown to be superior to Lugol chromoendoscopy in detecting ESCC [17]. In a systematic review and meta-analysis, the sensitivity and specificity of NBI endoscopy for the diagnosis of SPC of the esophagus were 97 and 94\%, respectively [18]. Positron emission tomography (PET)/computed tomography (CT) scan had been clinically useful for the staging, detecting distant metastases or SPC, and tumor surveillance of HNC [19], but it was reported to be unsuitable for screening and detecting early or superficial esophageal cancer [20]. Although routine endoscopic examination for SPC of the esophagus in HNC patients was advocated by studies on Asian populations [10, 21-25], it was not recommended by researchers from Western countries, except for patients with high-risk factors for SPC of the esophagus, such as tobacco or alcoholic exposure and specific sites of the primary HNC [18, 26-35].

Some studies have investigated the efficacy of PET/CT scan and compared the different endoscopic modalities in detecting esophageal SPCs, but a direct comparison between PET/CT scan and NBI endoscopy in newly diagnosed head and neck squamous cell carcinoma (HNSCC) patients had not been conducted. In the present retrospective study, we aimed to evaluate the role of $\mathrm{PET} / \mathrm{CT}$ scan, in comparison with NBI endoscopy, in detecting SPC of the esophagus in newly diagnosed HNSCC patients.

\section{Methods \\ Study design and data extraction}

The implementation of a universal NBI endoscopy screening program for patients with $\mathrm{HNC}$ had been initiated at the Endoscopy Center of Changhua Christian Hospital in Taiwan since November 2015. All patients were referred to gastroenterologists for NBI endoscopy, as part of the disease staging work-up. All patients provided written informed consent before endoscopic examination. The present retrospective study enrolled newly diagnosed HNC patients who underwent initial stage work-up by both PET/CT scan and NBI endoscopy and who received the complete treatment course at our hospital from November 2015 to November 2018. Patients who had been previously diagnosed with other malignancies, those did not complete the treatment course at our hospital, or those with incomplete follow-up data were excluded. This study was approved by the institutional review board of Changhua Christian Hospital (approval number: CCH IRB 180702).

\section{Protocol of NBI endoscopic examination}

All patients underwent endoscopic examination with an NBI system (Evis Lucera CLV-260NBI endoscopy, Olympus Medical Systems Corp., Tokyo, Japan). All endoscopic examinations and endoscopic submucosal dissection of ESCC were performed by four experienced endoscopists who had performed more than 500 endoscopy cases annually. After an overnight fast, the patients were asked to swallow a dose of simethicone solution, followed by local pharyngeal anesthesia with $10 \%$ xylocaine spray. First, the esophagus was examined from the esophageal inlet to the esophagogastric junction by conventional white-light endoscopy, followed by repeat evaluation from the distal to the proximal under NBI. A suspicious esophageal lesion was defined as a brownish discoloration of the mucosa, with abnormal vascular patterns under the NBI magnifying endoscopy system. Endoscopic biopsy was done for all suspicious lesions.

\section{Protocol for ${ }^{18} \mathrm{~F}$-FDG PET/CT scan}

Blood glucose levels were measured to check for potential hyperglycemia and patients had to stay sober for at least six hours before the intravenous injection of ${ }^{18} \mathrm{~F}$ FDG at $0.1-0.2 \mathrm{mCi} / \mathrm{kg}$. After ${ }^{18} \mathrm{~F}$-FDG administration, whole-body PET/CT scan was performed at $60 \mathrm{~min}$ and delayed regional imaging was performed at $120 \mathrm{~min}$. Non-contrast, low-dose CT scan from the skull vertex to the mid-thigh was conducted for attenuation correction and anatomical localization. All ${ }^{18}$ F-FDG PET/CT images were visually interpreted by an experienced nuclear 
medicine physicians, and an $\mathrm{SUV}_{\max }$ value $\geqq 3.5$ was highly considered as a positive PET/CT result $[36,37]$.

\section{Statistical analysis}

The extracted data were organized using Microsoft Excel software and were analyzed by MedCalc Statistical Software version 18.11 (MedCalc Software bvba, Ostend, Belgium; https://www.medcalc.org; 2018). Descriptive statistics, receiver operating characteristic curve (ROC), logistic regression analysis, independent Student's t-test, and Kaplan-Meier survival analysis were used to elaborate the demographic and crude estimates, to evaluate the diagnostic abilities of the examinations, to analyze the risk factors for the diseases of interest, to compare continuous variables between two groups, and to illustrate the survival outcomes of patients under specific circumstances, respectively. Statistical significance was considered for $p<0.05$.

\section{Results}

Initially, a total of 748 records of NBI procedures were identified from the database of the Endoscopy Center of Changhua Christian Hospital from November 2015 to November 2018. After excluding subjects based on our defined criteria, a total of 147 subjects were finally enrolled in the analysis (Fig. 1).

As shown in Table 1, the study population comprised $143(97.3 \%)$ men and had a mean \pm standard deviation age of $54.17 \pm 10.87$ years (range, $19-84$ years). Habitual consumption of alcohol, betel-nuts, and cigarettes were prevalent in our subjects, with percentages of 74.83 , 80.95 , and $89.16 \%$, respectively. The locations of the primary HNC were the nasopharynx $(N=3,2.04 \%)$; oral cavity $(N=98,66.67 \%)$; oropharynx $(N=17,11.56 \%)$; hypopharynx $(N=28,19.05 \%)$; and larynx $(\mathrm{N}=1,0.68 \%)$.
Only two patients had metastatic lesions of the primary $\mathrm{HNC}$ to the lung and liver, respectively. According to the American Joint Committee on Cancer Seventh Edition TNM Staging System, 20 (13.61\%) subjects were categorized as stage I; 22 (14.97\%) were stage II; $10(6.80 \%)$ were stage III; $91(61.90 \%)$ were stage IV; and $4(2.72 \%)$ were of unknown/inapplicable stage. Suspicious esophageal lesions were found by PET/CT scan in $8(5.44 \%)$ and by NBI endoscopy in 35 (23.81\%). Of $147 \mathrm{HNC}$ patients, $10.2 \%$ had ESCC $(N=10)$ and severe or high-grade dysplasia $(N=5)$ on pathologic examination of the endoscopic biopsy samples. In addition, gastric ulcer, duodenal ulcer, and positive Campylobacter-like organism test were identified in 39/144 (27.08\%), 32/145 (22.07\%), and 36/134 (26.87\%) of the patients, respectively.

On ROC analysis (Table 2), the respective sensitivities and specificities for ESCC detection were 50 and $97.81 \%$ for PET/CT scan and 100 and $81.75 \%$ for NBI endoscopy; the area under the curve (AUC) values were 0.739 [95\% confidence interval (CI), 0.660-0.808; $p=0.004$ ] for PET/ CT scan and 0.909 (95\% CI, 0.850-0.950; $p<0.001$ ) for NBI endoscopy (Fig. 2). In addition, the respective sensitivities and specificities for detecting suspicious esophageal lesions, including ESCC and high-grade dysplasia, were 33.33 and $97.73 \%$ for PET/CT scan and 100 and $84.85 \%$ for NBI endoscopy; the AUC values were 0.655 (95\% CI, $0.573-0.732 ; p=0.014)$ for PET/CT scan and 0.924 (95\% CI, 0.869-0.961; $p<0.001$ ) for NBI endoscopy (Fig. 3). The ROCs of PET/CT scan and NBI endoscopy were significantly different for detecting ESCC $(p=0.046)$ and for detecting suspicious esophageal lesions $(p<0.001)$.

The distribution of the detected esophageal lesions, according to the $\mathrm{T}$ classification, on PET/CT scan and NBI endoscopy is listed in Table 3. The AUCs for

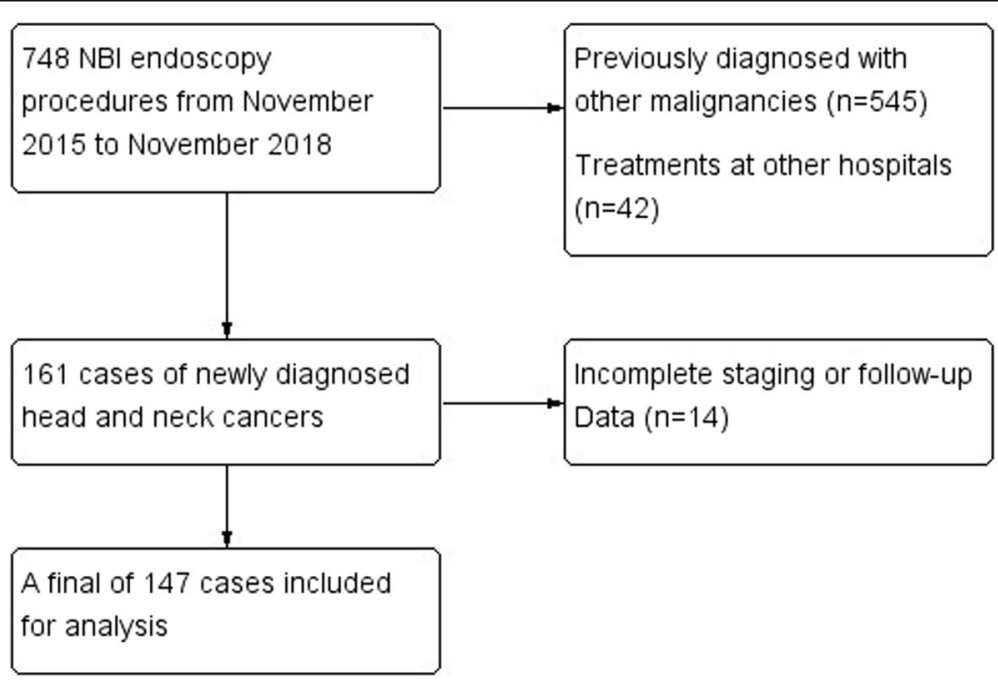

Fig. 1 Flowchart for study design 
Table 1 Basic characteristics of the subjects

\begin{tabular}{|c|c|}
\hline Characteristics & Values \\
\hline N & 147 \\
\hline $\operatorname{Sex}(M / F)$ & $143 / 4(97.3 \% / 2.7 \%)$ \\
\hline Age (mean, SD) & $54.17 \pm 10.87(19-84)$ \\
\hline \multicolumn{2}{|l|}{ Substance use } \\
\hline Alcohol consumption & $110(74.83 \%)$ \\
\hline Betel-nut consumption & $119(80.95 \%)$ \\
\hline Cigarette consumption & $131(89.16 \%)$ \\
\hline \multicolumn{2}{|l|}{ HNC tumor location } \\
\hline Nasopharynx & $3(2.04 \%)$ \\
\hline Oral cavity & $98(66.67 \%)$ \\
\hline Oropharynx & $17(11.56 \%)$ \\
\hline Hypopharynx & $28(19.05 \%)$ \\
\hline Larynx & $1(0.68 \%)$ \\
\hline \multicolumn{2}{|l|}{ Metastatic lesions } \\
\hline No & $143(97.28 \%$ \\
\hline Yes & $2(1.36 \%)$ \\
\hline Unknown & $2(1.36 \%)$ \\
\hline \multicolumn{2}{|c|}{ Seventh AJCC Staging of the HNSCC } \\
\hline Stage I & $20(13.61 \%)$ \\
\hline Stage ॥ & $22(14.97 \%)$ \\
\hline Stage III & $10(6.80 \%)$ \\
\hline Stage IVA & 65 (44.22\%) \\
\hline Stage IVB & $24(16.33 \%)$ \\
\hline Stage IVC & $2(1.36 \%)$ \\
\hline Unknown & $4(2.72 \%)$ \\
\hline \multicolumn{2}{|c|}{ PET/CT scan findings of the esophagus } \\
\hline Positive & $8(5.44 \%)$ \\
\hline Negative & 139 (94.56\%) \\
\hline \multicolumn{2}{|l|}{ Endoscopic findings } \\
\hline Suspicious esophageal lesion & 35 (23.81\%) \\
\hline Gastric ulcer & $39(27.08 \%)$ \\
\hline Duodenal ulcer & $32(22.07 \%)$ \\
\hline \multicolumn{2}{|c|}{ Pathologic findings in the esophagus } \\
\hline Squamous cell carcinoma & $10(6.80 \%)$ \\
\hline High-grade dysplasia & $5(3.40 \%)$ \\
\hline CLO test positivity & $36(26.87 \%)$ \\
\hline
\end{tabular}

AJCC American Joint Committee on Cancer, SD standard deviation, HNSCC head and neck squamous cell carcinoma, CLO Campylobacter-like organism

detecting superficial lesions (Tis and T1) were 0.539 for PET/CT scan and 0.924 for NBI endoscopy (Fig. $4 ; p<$ 0.001). On the other hand, the AUCs for detecting deep lesions (T2 and T3) were 0.889 for PET/CT scan and 0.924 for NBI endoscopy (Fig. 5; $p=0.725$ ).

The AUC of NBI endoscopy is not significantly different from that of PET/CT scan $(p=0.725)$.
Table 2 Comparison between PET/CT scan and NBI endoscopy

\begin{tabular}{|c|c|c|c|}
\hline & Sensitivity & Specificity & AUC \\
\hline \multicolumn{4}{|l|}{ ESCC } \\
\hline PET/CT scan & $50.00 \%$ & $97.81 \%$ & $0.739(0.660-0.808)$ \\
\hline $\mathrm{NBI}$ & $100.0 \%$ & $81.75 \%$ & $0.909(0.850-0.950)$ \\
\hline \multicolumn{4}{|c|}{ Suspicious esophageal lesions ${ }^{a}$} \\
\hline PET/CT scan & $33.33 \%$ & $97.73 \%$ & $0.655(0.573-0.732)$ \\
\hline $\mathrm{NBI}$ & $100.0 \%$ & $84.85 \%$ & $0.924(0.869-0.961)$ \\
\hline
\end{tabular}

The risk factors for SPC of the esophagus in the HNC patients were investigated by stepwise logistic regression. Among the variables, including age, sex, high-risk HNC location, and advanced stage of $\mathrm{HNC}$, only high-risk $\mathrm{HNC}$ location was predictive of the risk for development of SPC of the esophagus, with an odds ratio (OR) of 4.7 (95\% CI, $1.26-17.55 ; p=0.025)$. Likewise, the OR of high-risk HNC location for the development of suspicious esophageal lesions was 4.38 (95\% CI, 1.44-13.31; $p=0.012$ ).

The follow-up period ranged from 1 to 88.6 months, with a mean of 23.2 months. As shown in Fig. 6, the two-year overall survival rates of HNC patients were 44.56\% for those with ESCC and $57.70 \%$ for those without $\operatorname{ESCC}(p=0.5934)$.

Of the four endoscopists in the present study, two were high-volume endoscopists (115 cases) and the other two were relatively low-volume endoscopists (32 cases). Based

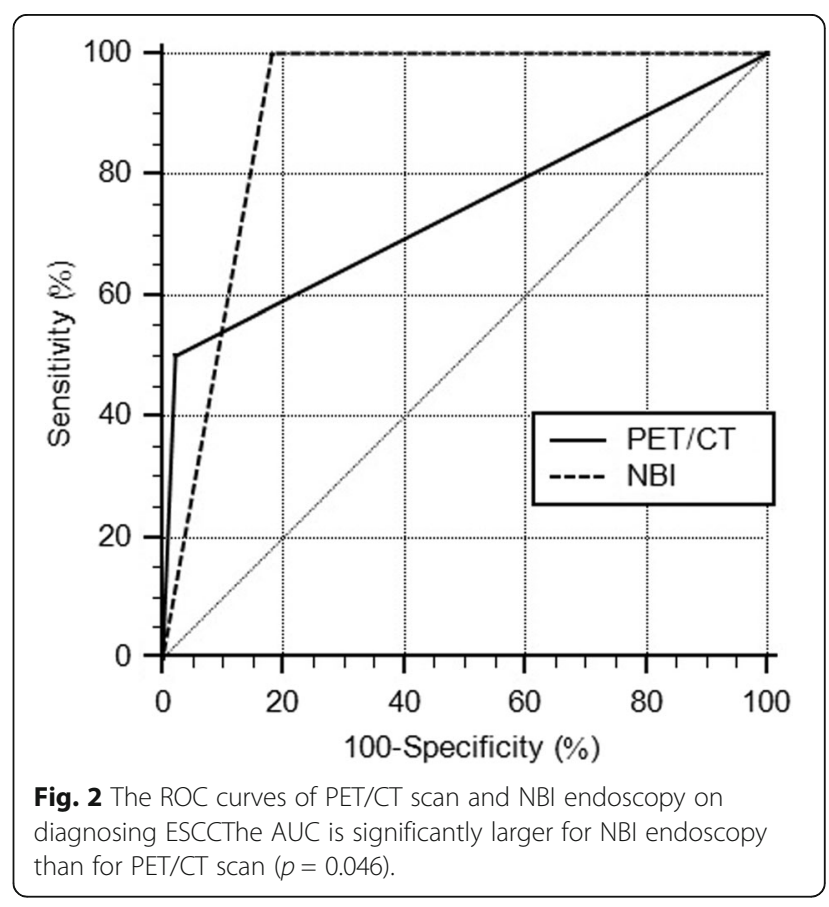




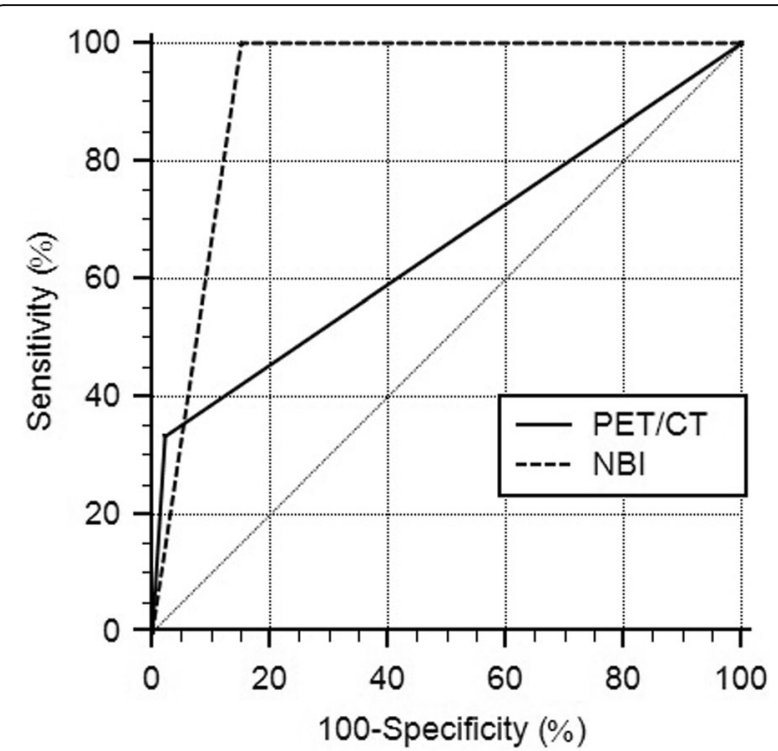

Fig. 3 The ROC curves of PET/CT scan and NBI endoscopy on diagnosing suspicious esophageal lesions The AUC is significantly larger for NBI endoscopy than for PET/CT scan $(p<0.001)$

on independent Student's t-test, there were no significant differences between the two groups of endoscopists in detecting ESCC $(p=0.8304)$ and suspicious esophageal lesions $(p=0.4096)$.

\section{Discussion}

In the present study, we aimed to compare the diagnostic abilities between NBI endoscopy and PET/CT scan for detecting SPC of the esophagus in HNC patients. This was the first report that directly compared the use of the two modalities for HNC patients. Our major findings revealed that compared with PET/CT scan, NBI endoscopy was superior and had $100 \%$ sensitivity for detecting ESCC and suspicious esophageal lesions, although its specificity was slightly lower. The higher AUC of NBI endoscopy, compared with that of PET/CT scan, implied the better performance of the former in detecting SPC of the esophagus in HNC patients.

A systematic review and meta-analysis reported similar results for NBI endoscopy, with $97 \%$ sensitivity and $94 \%$ specificity for detecting esophageal cancer in HNC patients [18]. In another study on a population that was not limited to HNC patients, NBI endoscopy yielded satisfactory sensitivity and specificity for diagnosing ESCC (88 and $88 \%$, respectively, on per-patient analysis; 94 and $65 \%$, respectively, on per-lesion analysis) [17]. The diagnostic performances of the different image-enhanced endoscopic (IEE) modalities had been compared in some studies. In a systematic review, NBI endoscopy performed better than Lugol chromoendoscopy in detecting SPC of the esophagus in HNC patients [18]. Another systematic review concluded that NBI endoscopy was superior to Lugol chromoendoscopy in the overall detection of ESCC [17]. A relatively recent analysis reported equivalent performances of the two in detecting early ESCC [38], but the use of NBI was more convenient and can prevent the potential harms (i.e., allergy) of iodine dye, compared with the use of Lugol chromoendoscopy [17].

Because the performance of endoscopy is operatordependent and requires clinical experience and skills, another advantage of NBI endoscopy over white-light endoscopy is that it can reduce operator dependence. The insignificant results by independent Student's t-test between high-volume and low-volume endoscopists suggested that the NBI endoscopy measurements were in acceptable agreement between the two groups of endoscopists. Although evaluation of interrater agreement could have been better analyzed by Cohen's kappa coefficient, our dataset lacked repeated measurements, which made kappa analysis not feasible. Further analysis of interrater agreements on NBI techniques is required.

Our results indicated imperfect performance of PET/ CT scan in detecting SPC of the esophagus. The limited spatial resolution of PET/CT scan was likely the primary cause of its inability to visualize early ESCC [39]. Moreover, ${ }^{18}$ F-FDG uptake had been shown to be positively correlated with the depth of ESCC $[40,41]$; therefore, superficial SCC was less likely to be detected on PET/ CT scan. Our results demonstrated that esophageal tumor depth or $\mathrm{T}$ classification was associated with the diagnostic abilities of PET/CT and NBI endoscopy. Likewise, other studies reported that PET/CT scan was suitable for deeper lesions, whereas endoscopy performed

Table 3 Esophageal lesions' distribution, according to the clinical T classification, and the diagnostic abilities of PET/CT and NBI

\begin{tabular}{llllll}
\hline T classification & ESCC or high-grade dysplasia & NBI-positive lesions & NBI-negative lesions & PET/CT-positive lesions & PET/CT-negative lesions \\
\hline Negative & 132 & 20 & 112 & 3 & 129 \\
Tis & 5 & 5 & 0 & 0 & 5 \\
T1 & 5 & 5 & 0 & 1 & 2 \\
T2 & 3 & 3 & 0 & 2 & 4 \\
T3 & 2 & 2 & 0 & 0 & 0 \\
T4 & 0 & 0 & 0 & & 0 \\
\hline
\end{tabular}




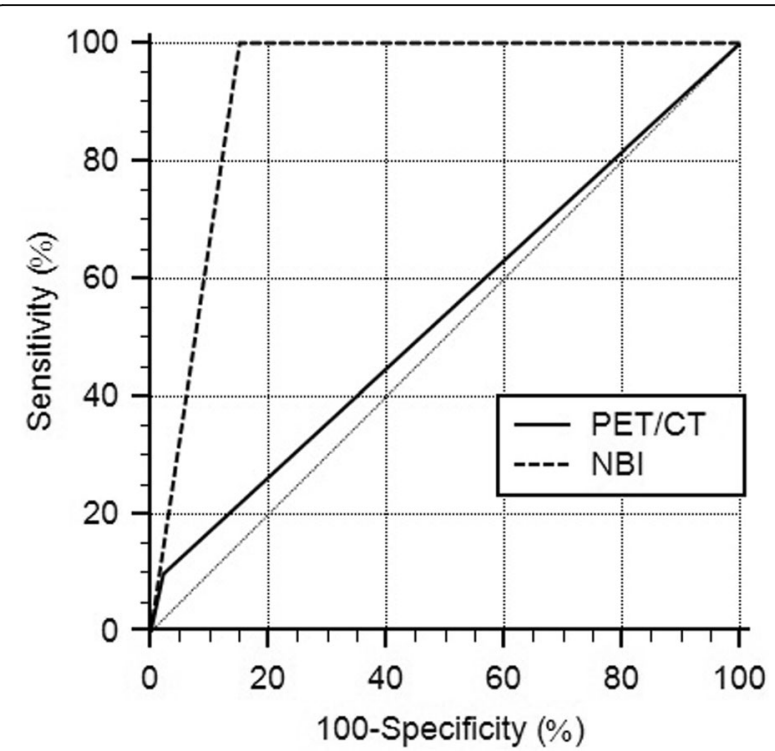

Fig. 4 PET/CT scan and NBI endoscopy's ROC curves on diagnosing superficial esophageal lesions (Tis and T1) The AUC of NBI

endoscopy is significantly larger than that of PET/CT scan $(p<0.001)$

well in identifying both deep and superficial lesions [5, 41]. Furthermore, false-positive PET/CT scan may be seen in numerous clinical situations, including gastroesophageal reflux disease, other esophageal inflammatory conditions, benign neoplasms, and increased uptake in normal tissues, such as the muscles [20,39]. Despite its inferior performance to NBI endoscopy in detecting SPC of the esophagus, $\mathrm{PET} / \mathrm{CT}$ scan remains indispensable for $\mathrm{HNC}$ patients. The various uses of PET/CT scan had been for disease staging,

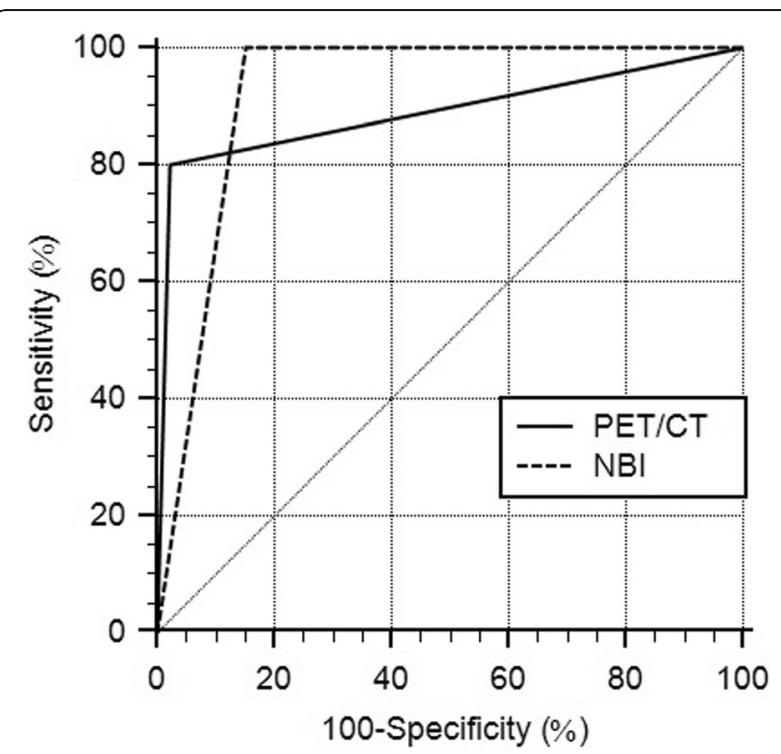

Fig. 5 PET/CT scan and NBI endoscopy's ROC curves on diagnosing deep esophageal lesions (T2 and T3)

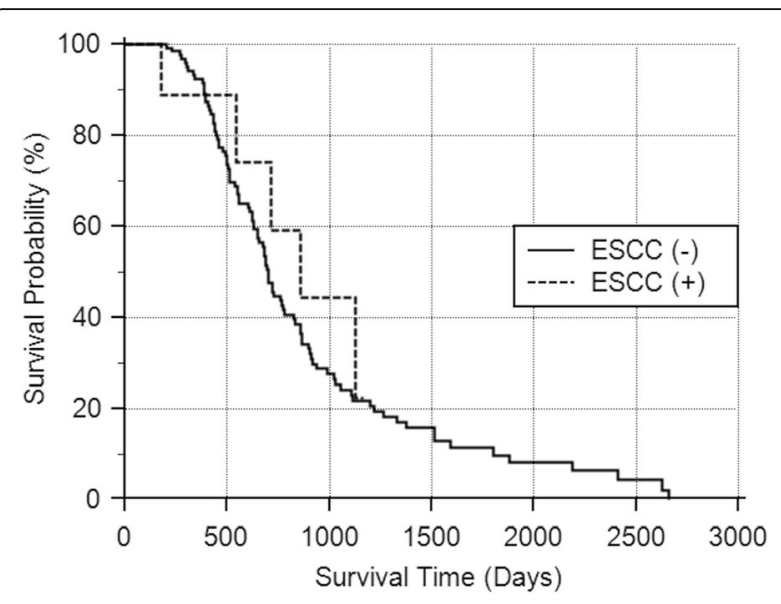

Fig. 6 The overall survival curves of HNC patients, according to the presence of ESCC. The overall survival rates are similar between patients with ESCC and those without ESCC $(p=0.5934)$

decision on treatment strategy, evaluation of prognosis, follow-up after treatment, and, most importantly, identification of unknown primary or metastatic neoplasms [19].

As previously mentioned, IEE had been advocated for routine screening for SPC of the esophagus in patients with HNSCC/HNC; however, most of the studies, including a systematic review and meta-analysis, were from far eastern countries [10, 18, 21-23]. In another systematic review, in which $80 \%$ of the included studies were from far eastern countries, IEE was strongly recommended for screening SPC in Asian populations; however, the role of IEE for screening remained unclear in Western populations [24]. Most of the published studies and clinical guidelines supported the role of routine IEE in high-risk populations only; among these publications, the descriptions of a high-risk population were variable and include the degree of tobacco and alcohol use; specific locations of the primary HNC, most were in the hypopharynx and larynx, as shown in our results; presence of esophageal symptoms; and ethnicity of the patients [28-32, 34, 35, 42].

Because the survival curves of our HNC patients did not differ according to the presence of ESCC, the benefit screening for SPC of the esophagus in HNC patients was not supported by our analyses. Nevertheless, the importance of screening for SPC of the esophagus cannot be overlooked. Early diagnosis of the SPC of the esophagus had been suggested [10, 14, 22, 23, 25, 43] or proven $[9,13,15,25]$ to have significant benefits on the prognosis and survival rates of patients. In addition, the treatment strategy was reported to vary according to the presence of ESCC [18, 44]; about $15.5 \%$ of $\mathrm{HNC}$ cases had their treatment strategies modified after identification of SPC of the esophagus by endoscopy [45]. Because of the ability of endoscopy to identify superficial lesions (Tis and T1), such 
as SPC of the esophagus, which are less likely to be discovered on PET/CT scan, surgical procedures for the esophageal lesions might need to be replanned or radiotherapy might need to be modified to cover the thoracic region in patients who would require concurrent chemoradiotherapy. In our analysis, all 10 patients diagnosed as ESCC were further treated by surgery $(N=1)$, endoscopic submucosal dissection $(N=3)$, and concurrent chemoradiotherapy $(N=6)$.

Because of the high incidence of SPC of the esophagus with primary $\mathrm{HNC}$ in Asian populations, the improvements in prognosis by early detection of SPC of the esophagus, and the dependence of the treatment strategy on the existence of an SPC, we propose, once again, the implementation of routine IEE examination, especially with NBI endoscopy, in all newly diagnosed HNC patients in Asian populations. ESCC has a high incidence in Asian populations, whereas esophageal adenocarcinoma accounts for most of the esophageal cancer cases in the Western countries [46]. Therefore, it would be reasonable to perform screening for SPC of the esophagus only for high-risk populations. In Taiwan, the role of endoscopy remains to be optional, according to the clinical guidelines for $\mathrm{HNC}$ published by the Taiwan Head and Neck Society in 2016 [47]. Since the cost per life-year of treatment for esophageal cancer is one of the highest expenditures among cancer therapies in Taiwan [48], early identification by endoscopic screening should be highly encouraged, in order to save the financial budget of the National Health Insurance in a more cost-effective way.

A systematic review reported that the global prevalence of peptic ulcer disease (PUD) was approximately 0.12 to $4.7 \%$ [49], and the prevalence of asymptomatic PUD in Taiwan was 9.4\% [50]. However, in the present study, we found a higher prevalence of PUD of up to $27.08 \%$. HNC and PUD share some common risk factors, such as smoking and betel nut chewing [50]. Furthermore, the primary care physician visits, specialist referrals, stress, and depression in HNC patients [51] likely predisposed these patients to have the other risk factors for PUD and may partially explain the high prevalence of PUD in our population. Although the risk factors for the development of PUD in HNC patients were not investigated in the present study, we would like to emphasize the high risk for PUD in HNC patients. In particular, physicians should be aware of the possibility of peptic ulcer bleeding after major therapeutic events, such as surgery, and should consider the use of protonpump inhibitors, whenever clinically indicated.

We acknowledged some limitations of the present study. First, the retrospective design made selection and reporting biases inevitable to a certain degree, and the limited sample size could have resulted to sampling bias. Second, endoscopy was performed by four examiners; there may have been inconsistencies among the operators, and interrater analysis was not feasible in the current dataset. Nevertheless, we believed that these limitations had little influence on our major objective of comparing the diagnostic ability between PET/CT scan and NBI endoscopy.

\section{Conclusions}

Based on the high incidence and great prognostic impact of SPC of the esophagus in HNC patients, PET/CT scan alone may be insufficient for the staging work-up of HNC, because it had considerable limitations in detecting early esophageal cancer in high-risk populations. The performance of NBI endoscopy was superior to $\mathrm{PET} / \mathrm{CT}$ scan in detecting SPC of the esophagus in HNC patients.

\begin{abstract}
Abbreviations
${ }^{18} \mathrm{~F}-\mathrm{FDG}:{ }^{18} \mathrm{~F}$-labeled fluoro-2-deoxyglucose; ESCC: Esophageal squamous cell carcinoma; HNC: Head and neck cancer; HNSCC: Head and neck squamous cell carcinoma; IEE: Image-enhanced endoscopy; NBI: Narrow-band imaging; PET: Positron emission tomography; PUD: Peptic ulcer disease; ROC: Receiver operating characteristic; SCC: Squamous cell carcinoma; SPC: Second primary cancer
\end{abstract}

\section{Acknowledgements}

The authors would like to thank Changhua Christian Hospital for the funding, and Enago (www.enago.tw) for the English language review. The authors would like to thank Professor Mu-Kuan Chen (Head of the Department of Otorhinolaryngology, Head and Neck Surgery, Changhua Christian Hospital, Changhua, Taiwan; Superintendent, Changhua Christian Hospital, Changhua, Taiwan) for supporting and referring patients for the NBI screening program in Changhua Christian Hospital since 2015.

\section{Authors' contributions}

HAS analyzed and interpreted the patient data and was a major contributor in writing the manuscript. SWH and YCH performed the endoscopy and interpreted the patient data. LYW accounted for the interpretation of PET/CT scans in the study and for revising the manuscript. HHY accounted for the research idea and study design, acquisition of data, data interpretation, and drafting of the manuscript. Each author contributed important intellectual content during manuscript drafting or revision and accepts accountability for the overall work, by ensuring that the questions pertaining to the accuracy or integrity of any portion of the work are appropriately investigated and resolved. All authors read and approved the final manuscript.

\section{Funding}

The authors received funding from the Changhua Christian Hospital (105-IRPCCH-009, 106-CCHIRP-030, and 108-CCH-IRP-018) for this manuscript.

\section{Availability of data and materials}

The datasets generated and/or analyzed during the current study are not publicly available, due to the privacy of the enrolled subjects, but these may be requested from the corresponding author, upon reasonable request.

Ethics approval and consent to participate

This retrospective study was approved by the institutional review board of Changhua Christian Hospital (approval number: CCH IRB 180702). All patients provided written informed consent before any form of clinical examination. The need for patient consent to data extraction was waived by the institutional review board, because the study involved minimal risk.

Consent for publication

Not applicable. 


\section{Competing interests}

The authors declare that they have no competing interests.

\section{Author details}

'Department of Medical Education, Kaohsiung Chang Gung Memorial Hospital, Kaohsiung, Taiwan. ${ }^{2}$ Endoscopy Center, Changhua Christian Hospital, 135 Nanhsiao Street, Changhua, Taiwan. ${ }^{3}$ Department of Nuclear Medicine, Changhua Christian Hospital, Changhua, Taiwan. ${ }^{4}$ Institute of Medicine, Chung Shan Medical University, Taichung, Taiwan. ${ }^{5}$ General Education Center, Chienkuo Technology University, Changhua, Taiwan.

Received: 3 July 2019 Accepted: 20 January 2020

Published online: 29 January 2020

\section{References}

1. Siegel RL, Miller KD, Jemal A. Cancer statistics, 2019. CA Cancer J Clin. 2019; 69(1):7-34.

2. Health Promotion Administration. Cancer Registry Annual Report, 2016. [Online]. Taiwan: Ministry of Health and Welfare; 2018. Available from: https://www.hpa.gov.tw/Pages/ashx/File.ashx?FilePath= /File/Attach/10227/ File_11644.pdf. Accessed 16 June 2019.

3. Scherübl $\mathrm{H}$, et al. Screening for oesophageal neoplasia in patients with head and neck cancer. Br J Cancer. 2002;86(2):239-43.

4. Priante AV, Castilho EC, Kowalski LP. Second primary tumors in patients with head and neck cancer. Curr Oncol Rep. 2011;13(2):132-7.

5. Nakaminato $\mathrm{S}$, et al. Prevalence of esophageal cancer during the pretreatment of hypopharyngeal cancer patients: routinely performed esophagogastroduodenoscopy and FDG-PET/CT findings. Acta Oncol. 2012; 51(5):645-52.

6. Day GL, Blot WJ. Second primary tumors in patients with oral cancer. Cancer. 1992;70(1):14-9.

7. Chuang SC, et al. Risk of second primary cancer among patients with head and neck cancers: a pooled analysis of 13 cancer registries. Int J Cancer. 2008;123(10):2390-6.

8. Chen MC, et al. Impact of second primary esophageal or lung cancer on survival of patients with head and neck cancer. Oral Oncol. 2010;46(4):249-54.

9. Lim H, et al. Clinical significance of early detection of esophageal cancer in patients with head and neck cancer. Gut Liver. 2015;9(2):159-65.

10. Hamada $Y$, et al. Esophageal squamous cell neoplasia is an independent negative prognostic factor for head and neck cancer patients. Int J Clin Oncol. 2018;23(2):243-8.

11. Liao $L-J$, et al. The impact of second primary malignancies on head and neck cancer survivors: a nationwide cohort study. PLoS One. 2013;8(4):-e62116.

12. Watanabe $\mathrm{S}$, et al. Impact of the early detection of esophageal neoplasms in hypopharyngeal cancer patients treated with concurrent chemoradiotherapy. Asia Pacific J Clin Oncol. 2017;13(2):e3-e10.

13. Chung CS, et al. Long term outcome of routine image-enhanced endoscopy in newly diagnosed head and neck Cancer: a prospective study of 145 patients. Sci Rep. 2016;6:29573.

14. Huang YC, et al. Regular screening of esophageal cancer for 248 newly diagnosed hypopharyngeal squamous cell carcinoma by unsedated transnasal esophagogastroduodenoscopy. Oral Oncol. 2016;55:55-60.

15. Wang WL, et al. The benefit of pretreatment esophageal screening with image-enhanced endoscopy on the survival of patients with hypopharyngeal cancer. Oral Oncol. 2013;49(8):808-13.

16. Ansari UH, et al. Validity of narrow band imaging in the detection of oral and oropharyngeal malignant lesions: a systematic review and metaanalysis. Head Neck. 2019;41(7):2430-40.

17. Morita FH, et al. Narrow band imaging versus lugol chromoendoscopy to diagnose squamous cell carcinoma of the esophagus: a systematic review and meta-analysis. BMC Cancer. 2017;17(1):54.

18. Chung CS, et al. Image-enhanced endoscopy for detection of second primary neoplasm in patients with esophageal and head and neck cancer: a systematic review and meta-analysis. Head Neck. 2016; 38(Suppl 1):E2343-9.

19. Escott EJ. Role of positron emission tomography/computed tomography (PET/CT) in head and neck cancer. Radiol Clin N Am. 2013;51(5):881-93.

20. Sekiguchi $M$, et al. Performance of 18-fluoro-2-deoxyglucose positron emission tomography for esophageal cancer screening. World J Gastroenterol. 2017;23(15):2743-9.
21. Wang WL, et al. Risk factors for developing synchronous esophageal neoplasia in patients with head and neck cancer. Head Neck. 2011;33(1):77-81.

22. Hung SH, et al. Routine endoscopy for esophageal cancer is suggestive for patients with oral, oropharyngeal and hypopharyngeal cancer. PLoS One. 2013;8(8):e72097.

23. Su YY, et al. Effect of routine esophageal screening in patients with head and neck cancer. JAMA Otolaryngol Head Neck Surg. 2013;139(4):350-4.

24. Bugter $\mathrm{O}$, et al. Early detection of esophageal second primary tumors using Lugol chromoendoscopy in patients with head and neck cancer: a systematic review and meta-analysis. Head Neck. 2019;41(4):1122-30.

25. Morimoto $M$, et al. Significance of endoscopic screening and endoscopic resection for esophageal cancer in patients with hypopharyngeal cancer. Jpn J Clin Oncol. 2010;40(10):938-43.

26. Shaha $A$, et al. Is routine triple endoscopy cost-effective in head and neck cancer? Am J Surg. 1988:155(6):750-3.

27. Petit $T$, et al. Systematic esophageal endoscopy screening in patients previously treated for head and neck squamous-cell carcinoma. Ann Oncol. 2001;12(5):643-6.

28. Guardiola E, et al. Is routine triple endoscopy for head and neck carcinoma patients necessary in light of a negative chest computed tomography scan? Cancer. 2004;101(9):2028-33.

29. Chow $\mathrm{TL}$, et al. Prediction of simultaneous esophageal lesions in head and neck squamous cell carcinoma: a multivariate analysis. Arch Otolaryngol Head Neck Surg. 2009;135(9):882-5.

30. McGarey PO Jr, et al. Rigid Esophagoscopy for head and neck Cancer staging and the incidence of synchronous esophageal malignant neoplasms. JAMA Otolaryngol Head Neck Surg. 2016;142(1):40-5.

31. Roland $\mathrm{N}$, et al. Tumour assessment and staging: United Kingdom National Multidisciplinary Guidelines. J Laryngol Otol. 2016;130(S2):S53-s58.

32. Nekhlyudov $L$, et al. Head and neck Cancer survivorship care guideline: American Society of Clinical Oncology clinical practice guideline endorsement of the American Cancer Society guideline. J Clin Oncol. 2017; 35(14):1606-21.

33. Sharma SJ, et al. Rigid triple endoscopy improves clinical staging of primary head and neck Cancer. Oncol Res Treat. 2018;41(1-2):35-8.

34. Blanchard D, et al. Guidelines update: post-treatment follow-up of adult head and neck squamous cell carcinoma: screening for metastasis and metachronous esophageal and bronchial locations. Eur Ann Otorhinolaryngol Head Neck Dis. 2015;132(4):217-21.

35. de Mones $E_{\text {, et }}$ al. Initial staging of squamous cell carcinoma of the oral cavity, larynx and pharynx (excluding nasopharynx). Part 2: Remote extension assessment and exploration for secondary synchronous locations outside of the upper aerodigestive tract. 2012 SFORL guidelines. Eur Ann Otorhinolaryngol Head Neck Dis. 2013;130(2):107-12.

36. Ogino I, et al. The importance of concurrent chemotherapy for T1 esophageal Cancer: role of FDG-PET/CT for local control. In Vivo. 2018;32(5):1269-74.

37. Stagg J, et al. Significance of 18F-Fluorodeoxyglucose uptake at the Gastroesophageal junction: comparison of PET to esophagogastroduodenoscopy. Dig Dis Sci. 2015;60(5):1335-42.

38. Gai W, et al. Efficacy of narrow-band imaging in detecting early esophageal cancer and risk factors for its occurrence. Indian J Gastroenterol. 2018;37(2):79-85.

39. Yang GY, et al. The role of positron emission tomography in esophageal cancer. Gastrointestinal Cancer Res. 2008;2(1):3-9.

40. Miyata $\mathrm{H}$, et al. Evaluation of clinical significance of 18F-fluorodeoxyglucose positron emission tomography in superficial squamous cell carcinomas of the thoracic esophagus. Dis Esophagus. 2008;21(2):144-50.

41. Kita $Y$, et al. Clinical significance of (1)(8)F-fluorodeoxyglucose positron emission tomography in superficial esophageal squamous cell carcinoma. Ann Surg Oncol. 2013;20(5):1646-52.

42. Wang YK, et al. Endoscopic screening for synchronous esophageal neoplasia among patients with incident head and neck cancer: prevalence, risk factors, and outcomes. Int J Cancer. 2017;141(10):1987-96.

43. Kagei $\mathrm{K}$, et al. Efficacy of intense screening and treatment for synchronous second primary cancers in patients with esophageal Cancer. Jpn J Clin Oncol. 2002;32(4):120-7.

44. Gong EJ, et al. Routine endoscopic screening for synchronous esophageal neoplasm in patients with head and neck squamous cell carcinoma: a prospective study. Dis Esophagus. 2016;29(7):752-9.

45. Chung C-S, et al. Risk factors for second primary neoplasia of esophagus in newly diagnosed head and neck cancer patients: a case-control study. BMC Gastroenterol. 2013;13:154. 
46. Domper Arnal MJ, Arenas AF, Arbeloa AL. Esophageal cancer: Risk factors, screening and endoscopic treatment in Western and Eastern countries. World I Gastroenterol. 2015;21(26):7933-43.

47. Taiwan Head and Neck Society. Clinical Guideline of Systemic Treatment for Head and Neck Cancers. [Online]. Taiwan: Taiwan Head and Neck Society; 2016. Available from: http://www.thns.org.tw/files/201605TaiwanHNC_ guidelines_0511.pdf. Accessed 20 June 2019.

48. Wu TY, et al. Lifetime risks, loss of life expectancy, and health care expenditures for 19 types of cancer in Taiwan. Clin Epidemiol. 2018;10:581-91.

49. Sung JJ, Kuipers EJ, El-Serag HB. Systematic review: the global incidence and prevalence of peptic ulcer disease. Aliment Pharmacol Ther. 2009;29(9): 938-46.

50. Wang FW, et al. Prevalence and risk factors of asymptomatic peptic ulcer disease in Taiwan. World J Gastroenterol. 2011;17(9):1199-203.

51. Gonzalez-Perez A, et al. Risk factors associated with uncomplicated peptic ulcer and changes in medication use after diagnosis. PLoS One. 2014;9(7): e101768.

\section{Publisher's Note}

Springer Nature remains neutral with regard to jurisdictional claims in published maps and institutional affiliations.

Ready to submit your research? Choose BMC and benefit from:

- fast, convenient online submission

- thorough peer review by experienced researchers in your field

- rapid publication on acceptance

- support for research data, including large and complex data types

- gold Open Access which fosters wider collaboration and increased citations

- maximum visibility for your research: over $100 \mathrm{M}$ website views per year

At $\mathrm{BMC}$, research is always in progress.

Learn more biomedcentral.com/submissions 